\title{
Study on the Effect of Environmental Kuznets Curve on China's Economic Growth Based on Income Inequality
}

\author{
Juanjuan Qin \\ School of Economics, Shanghai University, Shanghai, China \\ qinjuansky@sin.com
}

Keywords: Income inequality; Environmental pollution; Environmental kuznets curve; Economic growth

\begin{abstract}
In this paper, using time-series data of China from 1981 to 2011, in the perspective of the income inequality expands Environmental Kuznets Curve and analysis the effects of environmental pollution, and by the impact of extending the four-quadrant diagram, draw the economic growth mechanism. The results show that: First, The EKC exists inverted U-shaped relationship based on income gap, and the effects of income inequality on environmental pollution is positive and lagged. Secondly, the effect of income gap on economic growth depends on the stage of economic development, it promotes economic growth in the early days of reforming, but blocking on the current. Therefore, in order to implement the scientific concept of development we should effectively suppress widening income gap to achieve sustained growth of China's economy healthy.
\end{abstract}

\section{基于收入差距研究环境库兹涅茨曲线对中国经济增 长的影响}

\author{
秦娟娟 \\ 上海大学经济学院, 中国 上海 200444 \\ aqinjuansky@sin.com
}

摘要: 本文利用我国 1981-2011 年的时间序列数据, 在收入差距视角下扩展环境库兹涅茨曲线, 分析收入差距对环境污染的影响, 并在四象限图中延伸, 得出收入差距对经济增长的影响机制。研 究发现: 首先, 基于收入差距的环境库兹涅茨曲线存在倒 U 型曲线关系, 且收入差距对环境污染 的影响显著为正。其次, 收入差距对经济增长的影响取决于经济发展阶段, 改革初期的收入差距促 进了经济增长, 而现阶段却产生阻滞作用。因此, 为落实科学发展观, 我们应该抑制收入差距的扩 大, 以实现经济的可持续发展。

关键词：收入差距;环境污染;环境库兹涅茨曲线;经济增长

\section{1. 引言}

改革开放以来, 我国的经济呈现高速发展的态势, 1978-2014年, 我国人均GDP 从381元增加到46629 元, 增长了约 122 倍。然而, 一个不容忽视的事实是, 经济的快速发展在很大程度上是以牺牲环境为 代价的。统计数据表明: 2014 年我国废水排放量为 716.2 亿吨; 废气中二氧化硫的排放量约为 1974 万吨, 氮氧化物的排放量约为 1404.5 万吨, 不断恶化的环境质量严重制约了我国经济的长期持续 发展。另外, 快速发展相伴随的突出问题就是收入差距特别是城乡收入差距的持续扩大, 全国总体 的基尼系数由 1981 年的 0.29 上升到 2014 年的 0.469 。国际发展经验表明, 当人均GDP位于 1000 美元 
左右时, 收入差距的扩大很可能影响经济的长期增长。由此引出的问题是:第一、不断扩大的收入 差距水平是否会对环境污染产生不利影响?第二、如果是则通过什么样的途径影响环境污染的? 第三、收入差距的扩大对经济的长期增长是否已经产生阻滞效应? 第四、按照科学发展观的要求, 我国应采取什么政策调节收入差距以促进经济的长期增长? 考察这些问题即本文的研究动机。

\section{2. 理论综述}

早在20世纪90年代初期, Beckerman(1992)、Bhagawati(1993)等一些学者借鉴Kuznets关于收入分配 与经济发展之间的著名 “倒U型曲线” 论述, 指出经济发展与环境质量之间可能存在倒U型曲线关 系, 即在经济发展初期经济增长、人均收入的提高将会导致环境质量的下降, 然而一旦经济发展超 越某一临界值点, 人均收入的进一步提高反而会有助于降低环境污染、改善环境质量。受这一观 点启发, 大量学者运用各国截面、时序或者面板数据, 对是否存在环境库兹涅茨曲线进行了广泛研 究。Grossman and Krueger(1991)在分析北美自由贸易区协议(NAFTA)的环境效应时, 首次实证考 察了环境一收入倒U型关系的存在。国内一些著名学者对这一问题也进行了广泛的研究, 彭水军、 包群 (2006) 利用我国1996-2002年30个省市、自治区的面板数据对经济发展一环境污染之间的关 系进行实证检验, 不仅证实了 $\mathrm{EKC}$ 的存在, 还得出了经济增长一环境污染关系在不同经济区域及不 同发展阶段具有不同的差异的结论。

但理论上来说, 经济发展不仅包括经济总量的增长, 还涉及经济发展模式的变化, 仅仅用经济总量 的增长不能全面反映经济发展和环境污染之间的关系, 收入分配作为经济发展的另一面也应该纳 入到分析中来。Boyce(1994)最先研究了收入不平等与环境退化间的关系。他认为, 收入不平等将 从两个方面导致环境退化: 一是收入不平等现象会影响人们对环境利用的时间偏好, 二是收入不 平等现象会导致环境政策的偏离。Torres 、Boyce(1998) 以水及空气质量指标作为环境变量进行 了检验, 经验上证明了该结论。国内学者对此也有研究, 李海鹏 (2006) 使用当期的收入差距指标 对收入差距影响环境污染的机制作实证检验, 得出两点结论:第一、收入差距扩大会刺激二氧化碳 排放, 收入差距越大这种影响的效果就会越恶劣; 第二、收入差距因素还会通过作用于经济增长加 强环境的污染程度, 延迟转折点的到来。

事实上, 随着居民整体收入差距的不断上升, 收入差距对经济增长的作用机制并不明晰, 其作用效 果可能会随着时间而改变。因此, 本文在上述研究的基础上对环境库兹涅茨曲线进行扩展, 构建模 型研究收入差距对环境污染的影响, 并将这一模型通过四象限图进行传导, 来分析收入差距对经 济增长的影响机制。

\section{3. 理论基础}

本文假定人们对环境质量的需求决定了其环境治理的行为, 从而影响着环境质量的好坏。一般看 来, 绝对收入水平是影响环境治理能力的主要因素, 但部分地也取决于相对收入水平即收入差距。 因为当收入差距扩大时, 收入水平低的人群易于过度利用自然资源获取收入从而导致环境破坏加 剧, 而收入水平高的人则倾向于将财产转移到其他环境风险更低的地区, 对本地的环境治理支付 意愿不高, 因此伴随着收入差距的扩大, 不论是高收入水平群体还是低收入水平群体对环境的支 付意愿都会降低, 从而加重环境污染。综上所述, 人们对环境的治理可以表示为：

$\mathrm{C}=\mathrm{Y}\left(\pi-1 / 2 \pi^{2}\right)$

式(1)中C代表人们对环境的治理力度, 用一定时期内的环境治理投资额来表示, $Y$ 为收入水平, $\pi$ 为环境税率 $(0<\pi<1)$ 代表人们的环境支付意愿， $1 / 2 \pi^{2}$ 为政府在对环境进行投资时的执行成本， 因此, 总体环境治理投资额应为 $Y\left(\pi-1 / 2 \pi^{2}\right)$ 。 
另外, 从上面的分析可知, 随着收入差距水平的增大, 环境治理无论是对收入低的人还是对收入高 的人所带来的效用都会相对有所减少, 因此总体效用可以表示为税后收入加上环境治理与收入差 距的比值。如下所示:

$\mathrm{U}=(1-\pi)+\lambda \frac{C}{G I N I}$

其中, GINI代表的是收入差距水平, $\lambda$ 为调整系数。将 (2) 式对 $\pi$ 进行一阶求导, 可以得到效用最大 化时的环境税率:

$\pi=1-\frac{G I N I}{\lambda}$

从 (3) 式可以看出: 随着收入差距GINI的不断上升, 环境支付意愿 $\pi$ 不断下降, 从而使环境治理水 平下降, 环境污染加重。收入差距通过影响环境治理的支付意愿从而对环境质量产生影响。而对 于这类研究在国内并不多见, 但是比较库兹涅茨理论和环境库兹涅茨理论, 可以发现环境污染、 经济增长、收入差距之间存在着某种联系。从理论上讲, 虽然一定程度上的收入差距有助于经济 增长, 但一旦收入差距超过一定程度, 就会阻碍经济增长。由于人均GDP与环境质量存在倒U关系, 因此收入差距通过影响环境质量进而影响经济增长是必然存在的, 但这种影响可能是变动或不确 定的。

因此, 根据上述的理论分析, 我们提出两个基本假设：一是收入差距扩大会显著性地加重环境污 染; 二是收入差距的扩大会以牺牲环境为代价带来经济增长, 但这一增长效应并不能持续。本文研 究的出发点是引进反映收入差距的基尼系数指标来修正EKC理论模型, 然后通过四象限图将这一 影响扩展到收入差距对经济增长的影响上, 从而达到对这两个假定的验证。

\section{4. 数据、模型与分析}

4.1. 模型构建与数据的选取

理论上来讲, 环境污染除了受到经济发展水平和收入差距的影响, 同时还需要考虑人口密度、资源 禀赋、技术条件等因素的作用, 本文在研究中剔出了该类变量, 以反映出经济发展和收入差距对环 境污染的净影响。本文的计量模型是在传统的EKC理论模型上的一次扩展, 在研究中一般认为环境 污染与人均GDP的关系呈现倒U型。一般来说, 这种倒U型曲线的基本函数有二次函数型与三次函数 型。因此, 本文具体地模型的函数形式为:

$\mathrm{Wt}=\beta 0+\beta 1 \mathrm{PGDPt}+\beta 2 \mathrm{PGDPt} 2+\beta 3 \mathrm{PGDPt} 3+\beta 4 \mathrm{GINIt}$

在 (4) 式中, W表示环境污染水平, 在本文的分析中, 采取中国人均二氧化碳的排放量作为衡量污 染水平的指标, 数据来自世界银行统计数据库。PGDPt、PGDP ${ }^{2}$ 与 $\mathrm{PGDPt}^{3}$ 分别表示第 $\mathrm{t}$ 年的人均GDP、 人均GDP的平方与人均GDP的立方, 用以衡量经济发展水平, 数据来源于世界银行统计数据库, 指标 是以 2005 年不变价计算的人均GDP, 本文在模型的检验中采用 1000 美元作为计算单位。在大多数有 关收入分配和环境关系的研究中均选取基尼系数作为分析对象，在我们的分析中，也采取该类 研究数据, 1981-2002年基尼系数是采用的程永宏 (2007) 估计的数据, 2003-2011年的基尼系数是 中国统计年鉴公布的数据。数据时段为1981-2011年。

4. 2 . 检验结果

我们对原始模型进行检验,将样本数据带入以上模型，从而得到检验方程，如下所示： 
表1 收入差距与环境污染的回归结果

\begin{tabular}{|c|c|c|c|c|}
\hline Variable & Coefficient & Std.Error & t-Statistic & Prob. \\
\hline Bo & 0.323044 & 0.446975 & 0.722733 & 0.4763 \\
\hline PGDP & -1.162845 & 0.774269 & -1.501862 & 0.1452 \\
\hline PGDP $^{2}$ & 1.403423 & 0.427208 & 3.285109 & 0.0029 \\
\hline PGDP $^{3}$ & -0.213989 & 0.079432 & -2.693992 & 0.0122 \\
\hline GINI & 5.723005 & 1.905862 & 3.002843 & 0.0058 \\
\hline R-squared & 0.984130 & \multicolumn{4}{|c|}{ Durbin-Watson stat } & 0.762430 \\
\hline F-statistic & 403.0670 & \multicolumn{4}{|c|}{ Prob(F-statistic) } & 0.000000 \\
\hline
\end{tabular}

从回归结果来看, 该方程相关系数 $\mathrm{R}^{2}$ 为 0.9841 , 回归方程的显著性检验 $\mathrm{F}$ 值为403.0670, DW检验为 0.762 , 方程总体拟合较好, 但PGDP项回归系数没有能通过验验, 其他变量系数显著性水平较高, 表明方程可能存在一个无关变量PGDP, 模型拟合过度。

4.3. 模型设定误差检验

针对上述模型中存在变量不显著的情况, 本文对每一变量进行Wald检验, 从而找出圥余变量, 具体 的结果如下所示:

表2 Wald检验结果

\begin{tabular}{|c|c|c|c|}
\hline 原假设: & Chi-square 统计量 & $\mathbf{P}$ 值 & 结论: \\
\hline $\boldsymbol{\beta}_{\mathbf{0}}=\mathbf{0}$ & 2.255590 & 0.1331 & 接受 \\
\hline $\boldsymbol{\beta}_{\mathbf{2}}=\mathbf{0}$ & 10.79194 & 0.0010 & 拒绝 \\
\hline $\boldsymbol{\beta}_{\mathbf{3}}=\mathbf{0}$ & 7.257591 & 0.0071 & 拒绝 \\
\hline $\boldsymbol{\beta}_{\mathbf{4}}=\mathbf{0}$ & 9.017067 & 0.0027 & 拒绝 \\
\hline
\end{tabular}

从检验结果可以看出, 在 0.05 的显著性水平下, 我们可以接受变量PGDP项系数为 0 的约束条件, 而 不能接受其他变量的约束条件, 因此, 本文认为变量PGDP为模型的圥余变量。因此, 本文剔除了人 均GDP一次方项, 得到修正后的模型, 并对方程重新进行估计。其估计结果如下所示：

$\mathrm{W}=0.6868+0.7984 \mathrm{PGDP}^{2}-0.1135 \mathrm{PGDP}^{3}+3.4334 \mathrm{GINI}$
$(1.787)^{*}$
$(5.488)^{* * *}$
$(-2.594)^{* * *}$
$(2.934)^{* * *}$

$\mathrm{R}^{2}=0.9828 \quad \mathrm{DW}=0.595$

（注：******分别表示在 $10 \%, 5 \%, 1 \%$ 水平上具有统计显著性）

从修正后方程的回归结果来看, 该方程复相关系数 $\mathrm{R}^{2}$ 为 0.9841 , 调整后的 $\mathrm{R}^{2}$ 为 0.9828 , 回归方程 的显著性检验 $F$ 值为 512.823 , DW检验为 0.593 , 回归误差设定检验RESET接近 0 , 截距项回归系数通 过 $5 \%$ 显著性检验, 解释变量PGDP ${ }^{2}$ 、 $\mathrm{PGDP}^{3}$ 与 GINI回归系数均在 $1 \%$ 水平下显著, 因此上述拟合方程可 以作为最优方程, 进行以下分析。

\section{4. 检验结果分析}

为分析在控制其他变量不变的情况下, 收入差距以及经济增长对环境污染的单独影响, 我们对环 境污染回归方程分别求GINI和PGDP的一阶导：

$$
\frac{\partial W}{\partial G I N I}=3.4334
$$


(6) 式表明在控制经济发展水平不变的情况下, 收入差距变化对环境污染的影响。其一阶导数为正 值, 这意味着当收入差距不断扩大时, 环境污染的程度也在不断加深, 说明在控制其他条件的情况 下, 收入差距扩大会刺激二氧化碳排放, 且收入差距越大, 这种影响会越恶劣。因此, 现阶段缩小 收入差距, 将对环境质量提高具有重要意义。

我们在控制收入差距不变的情况下，对回归方程求PGDP的一阶导来分析人均GDP对环境污染的影 响:

\title{
$\frac{\partial W}{\partial P G D P}=1.5968 \mathrm{PGDP}-0.3405 \mathrm{PGDP} 2=0$
}

(7) 式表明环境污染与人均GDP之间是一种倒N型关系, 但实际情况人均GDP必然大于 0 , 在这一条件 下, PGDP对环境污染方程的一阶导是先为正值后为负值, 基本符合倒U型特征, 这和其他学者研 究结果是一致的。当一阶导数等于 0 时, 达到曲线的拐点, 此时 $P G D P=4.6895$ (1000美元), 从表 3 中我 们可以看出中国 2014 年的人均GDP为 3863.9 美元 (按 2005 不变价), 与曲线的拐点 4689.5 美元相差 不多, 表明近几年中国经济会面临转型, 随着经济的不断增长, 环境污染的问题将会有所改善。 接下来, 我们对回归方程求PGDP的二阶导来分析经济增长对环境污染影响的速率：

\author{
$(\partial W)$ \\ $\partial^{2} P G D P=1.5968-0.681 \mathrm{PGDP}=0$
}

从式 (8) 我们可以看出, PGDP 对环境污染方程的一阶导是先为正值后为负值, 转折点为 $\mathrm{PGDP}=2.345$ (1000美元), 表明在这一人均GDP的水平下, 经济增长对环境污染影响的速率达到最大, 结合表3我们可知在2007、2008年经济增长对环境污染的影响速率最大。2000年后, 随着我国工业 产业复苏, 加上环保政策较前几年宽松, 经济加速增长, 使得C02排放量急剧增加, 到2008年经济增 长对 $\mathrm{C} 02$ 排放增长速率的影响达到最大, 表明我国经济增长仍然是加重二氧化碳排放量增加的, 技术、资金支持与产业结构调整仍然不足以实现二氧化碳排放的绝对逆转。

表3 2001-2014 中国人均GDP (按2005不变件, 单位: 美元)

\begin{tabular}{|c|c|c|c|c|c|c|c|}
\hline 年份 & 2001 & 2002 & 2003 & 2004 & 2005 & 2006 & 2007 \\
\hline 人均 GDP & 1212.15 & 1313.9 & 1436.5 & 1571.9 & 1740.1 & 1950.0 & 2215.2 \\
\hline 年份 & 2008 & 2009 & 2010 & 2011 & 2012 & 2013 & 2014 \\
\hline 人均 GDP & 2415.9 & 2625.9 & 2891.1 & 3150.2 & 3377.8 & 3619.4 & 3862.9 \\
\hline
\end{tabular}

数据来源: 世界银行统计数据库

\section{5. 收入差距对经济增长的影响机制}

从式(4)拟合的方程来看, 收入差距与环境污染之间存在正相关关系, 即较高的收入差距会使经 济增长加剧对 $\mathrm{CO} 2$ 排放量。为比较不同收入差距下的经济增长与环境污染之间的关系, 可以将 GINI系数分别取 $0.2 、 0.4$ 和 0.6 , 代入含参差项的回归方程, 得到相应收入差距下的 CO2排放量, 从而绘出不同收入差距下的环境库兹涅茨曲线, 如图1所示:

从图1可以看出,随着基尼系数升高, $\mathrm{EKC}$ 曲线会向上移动,其经济意义在于处于相同的经济发展状 况下收入差距的增大会导致环境恶化加重, 对经济增长有什么影响呢? 本文接下来通过四象限图 的传导机制来分析收入差距对经济增长速度的影响。 


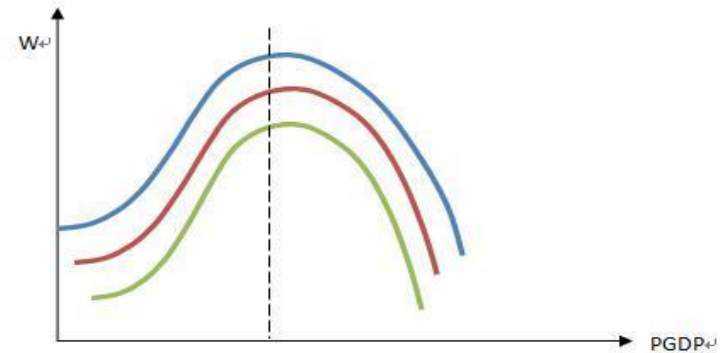

图1 不同收入差距下的 EKC 曲线

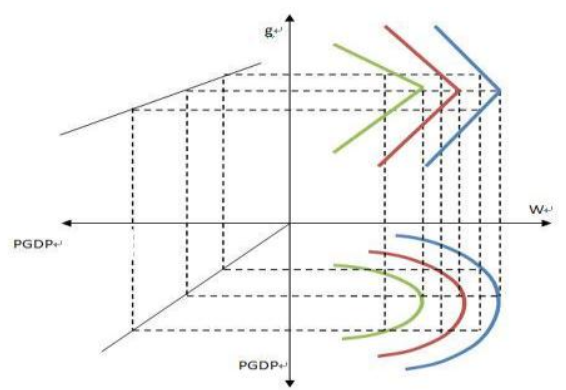

图2 收入差距对经济增长影响的传导机制

在图2中,第四象限代表的是EKC曲线,它代表的是人均 GDP与环境污染之间的关系,从上述的实证 分析我们可知 $\mathrm{EKC}$ 曲线呈倒 $\mathrm{U}$ 型, 在加入收入差距下的 $\mathrm{EKC}$ 曲线会随着收入差距的改变而发生移 动,在实证分析中我们可知收入差距对环境污染有正相关关系,因此,收入差距的扩大会使得EKC 曲线向上移动, 收入差距的减少会使得EKC曲线向下移动。第二象限代表的是经济增长速度与人均 GDP之间的关系, 一般情况下, 经济水平越高, GDP的增长速度会越小, 所以GDP的增长速度与人均 GDP呈负相关。通过二、三、四象限的传导机制, 我们可以得到环境污染与GDP增长速度之间的关 系, 随着人均GDP的不断提高, 经济增长速度逐渐下降, 但环境污染程度确实先上升后下降, 我们可 以得出经济增长速度与环境污染之间呈现一个 “>” 型的曲线关系, 而且这一曲线会随着收入差距 的改变而发生移动, 收入差距扩大时, “>” 型曲线向右移动, 收入差距缩小时 “>” 型曲线向左移 动。从另一个角度来看, 在人均GDP处于拐点之前时, 收入差距的扩大, 会使得曲线向上移动, 表明 在经济发展的初级阶段收入差距的扩大有利于促进经济的增长; 当人均GDP超过拐点, 收入差距的 扩大使得曲线向下移动, 表明此时收入差距的扩大导致了经济增长速度的下降。反之, 当经济发 展到一定水平下, 人均GDP超过拐点, 收入差距的缩小会使得曲线向上移动, 表明此时收入差距的 缩小有利于促进经济的发展。

由表3可知, 2014年我国人均GDP与拐点相差不多, 说明我国改革初期的城乡收入差距对经济增长 产生促进效应, 而现阶段或者以后收入差距的扩大对经济的长期增长产生阻滞作用, 这是本文的 主要结论。这一结论比较准确地刻画了我国收入差距与经济增长的真实情况, 改革初期, 物质资本 积累是我国经济发展的主要推动力, 适当的城乡收入差距, 有助于促进经济增长。随着我国经济转 型, 物质资本积累相对充裕, 经济增长更多依赖于科技进步, 而科技进步主要源于人力资本的提高, 但我国人力资本的水平与经济增长的水平相比较还较低, 特别是农村居民对人力资本的投入较少。 如果收入差距不断扩大使得农村居民对人力资本、教育的投入不够, 并依然以牺牲环境为代价获 得收入, 而资本对产出的边际贡献逐渐下降, 这一方式在现阶段不但不能促进经济的增长, 还会导 致环境的继续恶化, 正如 “>” 型曲线在收入差距扩大向下移动所示。

\section{6. 结论}

利用1981-2011年的时间序列数据, 本文分析了收入差距对我国环境污染的影响及其对经济增长 影响机制, 研究发现首先收入差距对环境污染的影响显著为正, 表明即收入差距会加重环境破坏。 从本文实证中可以看出, 收入差距会影响二氧化碳的排放量, 收入差距扩大会刺激二氧化碳排 放, 且收入差距越大, 影响会越恶劣。另一方面, 收入差距因素还会通过环境污染作用于经济增长, 加强对环境的污染程度。低收入人群通过牺牲环境换取物质资本, 使得物质资本得到积累与深化, 这在初级阶段促进经济的增长。现阶段我国收入差距过大不仅会导致环境恶化, 还会抑制经济的 转型升级, 不利于农村人力资本的形成, 抑制经济增长。因此, 在重视经济增长对环境的改变的同 
时, 也必须重视收入分配对环境与经济增长的影响, 经济增长要以社会整体福利提高为目的, 协 调公平和效率的关系，缩小居民收入差距。

\section{参考文献}

[1] Simone Borghesi. Income Inequality and the Environmental Kuznets Curve[R]. Center working paper.2000.

[2] Boyce. Inequality as a cause of environmental degradation [J]. Ecological Economics,1994,No.11, p.169-178.

[3] Torras,Boyce. Income inequality and pollution: a reassessment of the environmental Kuznets curve [J]. Ecological Economics, 1998,No.25, p.147-160.

[4] 贺彩霞, 由茂盛. 环境污染与经济增长一基于省际面板数据的区域差异研究 $[\mathrm{J}]$. 中国人口 - 资 源与环境,2009,No.2, p.56-62.

[5] 彭水军,包群. 经济增长与环境污染一环境库兹涅茨曲线假说的中国检验 [J]财经问题研 究,2008,No.8, p.3-17.

[6] 王少平,欧阳志刚.我国城乡收入差距的度量及其对经济增长的效应[J]经济研究,2007, No.10, p.44-55.

[7] 李海鹏,叶慧,张俊逖.中国收入差距与环境质量关系的实证检验一一基于对环境库兹涅茨曲线 的扩展 $[\mathrm{J}]$ 中国人口・资源与环境,Vol.16(2006), No. 2, p.46-50.

[8] 程永宏.改革以来全国总体基尼系数的演变及其城乡分解 [J]中国社会科学,2007,No.4, p. 45-60.

[9] 胡志军. 基于分组数据的基尼系数估计与社会福利:1985-2009年[J]数量经济技术经济研究, 2012,No.9, p. 111-121.

[10]潘丹,应瑞瑶. 收入分配视角下的环境库兹涅茨曲线研究一一基于1986-2008年的时序数据 分析[J]中国科技论坛,2010,No.6, p. 94-98.

\section{References}

[1] Simone Borghesi. Income Inequality and the Environmental Kuznets Curve [R]. Center working paper. 2000.

[2] Boyce. Inequality as a cause of environmental degradation [J]. Ecological Economics,1994,No.11, p.169-178.

[3] Torras,Boyce. Income inequality and pollution: a reassessment of the environmental Kuznets curve [J]. Ecological Economics, 1998,No.25, p.147-160.

[4] He Caixia, Ran Maosheng. Enviromental pollution and economic growth: research based on China' sprovincial data for difference areas [J].China Population Resources and Enviroment,2009,No.2, p.56-62.

[5] Peng Shuijun,Bao Qun.Economic growth and environmental pollution: An empirical test for the environmental Kuznets curve hypothesis in China [J].Research on Financial and Economic Issues, 2008, No. 8, p.3-17. 
[6] Wang Shaoping,Ouyang Zhigang. The rural-urban income disparity and its effects to ecomomic growth in the case of China[J].Economic Research,2007, No.10, p.44-55.

[7] Li Haipeng,Ye Hui,Zhang Junbiao.An empirical test on therelationship between income inequality and environmental quality in China: extensions of environmental Kuznets curve[J].China Population Resources and Enviroment,Vol.16(2006), No. 2, p.46-50.

[8] Cheng Yonghong.China' s overall Gini coefficient since reform and its decomposition by rual and urban areas since reform and opening-up[J].China Social Sciences, 2007,No.4, p. 45-60.

[9] Estimation for Gini coefficient based on grouped data and the social welfare: 1985-2009[J].2012, No. 9, p. 111-121.

[10]Pan Dan,Ying Ruiyao.Study on the environmental Kuznets curve in the view of income distribution[J].China Science and Technology Forum,2010,No.6,p. 94-98.

作者简介: 秦娟娟 (1989-), 女, 河南安阳, 上海大学研究生, 产业经济学, qinjaunsky@sina. com 